\title{
Differential Effects of Short and Long Durations of Insulin-Induced Maternal Hypoglycemia upon Fetal Rat Tissue Growth and Glucose Utilization
}

\author{
FREDERICK L. LUEDER, CAROLEE A. BUROKER, SUN-BUM KIM, ANNETTE S. FLOZAK, AND \\ EDWARD S. OGATA \\ Department of Pediatrics, Northwestern University Medical School, Evanston Hospital, Evanston, Illinois 60201 \\ and Department of Pediatrics, Children's Memorial Hospital, Chicago, Illinois 606/4
}

\begin{abstract}
We studied the effects of short and long durations of insulin-induced maternal hypoglycemia upon in vivo glucose utilization of several fetal tissues in the rat. Osmotic minipumps filled with insulin were implanted in pregnant rats on d 15 or 18 of gestation (term $21.5 \mathrm{~d}$ ), and radiolabeled 2-deoxyglucose was used to measure relative glucose utilization rates (rGU) of fetal liver, lung, muscle, kidney, heart, placenta, and brain on $d 20$ of gestation after 2 or $5 \mathrm{~d}$ of hypoglycemia. Maternal plasma glucose concentrations decreased within $24 \mathrm{~h}$ of pump placement and remained less than controls throughout gestation. Fetal plasma glucose and insulin concentrations on d 20 were equally reduced after 2 and $5 \mathrm{~d}$ of hypoglycemia. Both 2 and $5 \mathrm{~d}$ of hypoglycemia were associated with significant reductions in the rGU of fetal liver, lung, and muscle. Reductions in fetal kidney rGU also occurred after 2 and $5 \mathrm{~d}$ of hypoglycemia but to a smaller degree. rGU of fetal heart was reduced after 2 d of hypoglycemia, but was normal after $5 \mathrm{~d}$ of hypoglycemia. Both 2 and $5 \mathrm{~d}$ of hypoglycemia were associated with increased rGU of fetal brain. Five d, but not 2 d of hypoglycemia resulted in decreased fetal weight on $\mathrm{d} \mathbf{2 0}$ of gestation. However, at term, newborn pups delivered of hypoglycemic mothers weighed significantly less than controls regardless of the timing of minipump placement. Liver, lung, and carcass of these growth-retarded pups weighed less than control tissues, whereas kidney, heart, and brain weights were not affected. We speculate that fetal tissue growth and glucose utilization are influenced by common mechanisms and that glucose utilization may be an important determinant of fetal tissue growth. (Pediatr Res 32: 436-440, 1992)
\end{abstract}

\section{Abbreviations}

rGU, relative glucose utilization

IUGR, intrauterine growth retardation

2DG, 2-deoxyglucose

2DG6P, 2-deoxyglucose-6-phosphate

$\mathbf{P}_{\mathbf{k}}$, placental discrimination constant

IUGR is a frequently occurring obstetrical problem associated with an increased incidence of perinatal mortality and morbidity. Limited metabolic fuel availability to the fetus is an important factor in the development of IUGR. Decreased availability of maternally derived glucose is responsible for diminished plasma

Received December 11, 1991; accepted May 28, 1992.

Correspondence: Frederick L. Lueder, M.D., Department of Pediatrics, Evanston Hospital, 2650 Ridge Ave., Evanston, IL 60201. glucose and insulin concentrations in growth-retarded human fetuses $(1,2)$. Fetal hypoglycemia and hypoinsulinemia, in turn, are major factors retarding fetal growth; glucose is a primary fetal metabolic substrate and insulin is a key growth-stimulating hormone that has mitogenic and numerous anabolic effects.

The effects of limited glucose availability upon fetal growth is apparently tissue-specific because IUGR often results in asymmetric fetal growth, i.e. limited somatic but normal brain growth. The mechanisms for this phenomenon are not completely understood. Whether glucose utilization of specific tissues reflects these differential growth patterns under conditions of limited glucose availability is not known and is the focus of this study.

We previously studied the effects of maternal uterine artery ligation upon fetal tissue rGU (3). rGU of placenta, liver, muscle, and brain were decreased $24 \mathrm{~h}$ after ligation. However, at $48 \mathrm{~h}$, rGU of fetal liver, muscle, heart, and kidney were increased despite persistent fetal hypoglycemia. Fetal brain rGU was similar to control at this time. It is possible that fetal hypoxia and acidosis, which occur after uterine artery ligation (4), were responsible for this paradoxical increase in rGU of fetal tissues.

To address the role of limited glucose availability without hypoxia and acidosis upon fetal tissue glucose utilization, we used another model of IUGR in which a continuous infusion of insulin produces maternal hypoglycemia (5). This technique limits glucose availability, resulting in fetal hypoglycemia and hypoinsulinemia, but does not alter placental gaseous exchange (6). The ensuing degree of IUGR is less severe than with maternal uterine artery ligation and thus may be more representative of milder forms of uteroplacental insufficiency or other causes of IUGR not associated with altered gaseous exchange. To assess fetal tissue response to variable durations of hypoglycemia, we chose to study fetal tissue rGU after 2 and $5 \mathrm{~d}$ of maternal hypoglycemia initiated at different days of gestation.

\section{MATERIALS AND METHODS}

Animals and surgical procedures. On d 15 or 18 of gestation (term $21.5 \mathrm{~d}$ ), pregnant Sprague-Dawley rats (Harlan Laboratories, Madison, WI) were anesthetized with $8 \mathrm{mg} / \mathrm{kg}$ xylazine and $40 \mathrm{mg} / \mathrm{kg}$ ketamine, intraperitoneally. An insulin-filled, osmotic minipump (Alzet model 2002, Alza Corp., Palo Alto, CA) was implanted into the subcutaneous tissue of the dorsum of each rat's neck. Minipumps were filled with regular porcine insulin, $450 \mathrm{U} / \mathrm{mL}$ (Iletin-2, Eli Lilly Co., Indianapolis, IN), and placed in normal saline $24 \mathrm{~h}$ before implantation. Once implanted, the pumps continuously delivered $225 \mathrm{mU}$ insulin per $\mathrm{h}$ for the remainder of gestation. The left jugular vein and carotid artery were catheterized with sterile polyvinyl tubing at the time of pump placement. Two groups of control rats $(2$ and $5 \mathrm{~d}$ ) were anesthetized and catheterized, but did not receive insulin. All rats had free access to standard food and water. In addition, rats 
receiving insulin were allowed access to a dextrose solution (100 $\mathrm{g} / \mathrm{L} \mathrm{H}_{2} \mathrm{O}$ ) for $24 \mathrm{~h}$ after surgery to prevent fatal hypoglycemia. This protocol was approved by the Animal Care Committees of Children's Memorial and Evanston Hospitals.

Glucose utilization studies. We used a modification of Sokoloff's 2DG method (7-9) to measure rGU of several fetal rat tissues on $\mathrm{d} 20$ of gestation after 2 and $5 \mathrm{~d}$ of hypoglycemia. The description of the methodology and its validation have been discussed previously (3). In brief, eight or nine maternal rats in each of the four groups were injected with $370 \mathrm{kBq}$ of $2 \cdot\left[{ }^{3} \mathrm{H}(\mathrm{G})\right]$ -deoxy-D-glucose (New England Nuclear, Boston, MA; sp act $263 \mathrm{kBq} / \mathrm{nmol}$ ) through the jugular catheter. Maternal arterial blood was obtained at $1,3,5,10,15,20,25,30,35$, and 43 min after injection. At $45 \mathrm{~min}$, four fetuses from the mid portion of the uterine horns were removed, weighed, decapitated, and frozen in liquid nitrogen. Approximately $100-\mathrm{mg}$ portions of the placenta (villous chorion), liver, and lung and the entire heart, brain, kidney, and hind limb muscles were removed from each frozen fetus and weighed. Fetal tissue rGU was calculated using the following equation:

$$
\mathrm{rGU}=\frac{[2 \mathrm{DG} 6 \mathrm{P}] \mathrm{T}(\text { fetal tissue })}{\mathrm{P}_{\mathrm{k}} \int_{0}^{\mathrm{T}} \frac{[2 \mathrm{DG}] \mathrm{t}}{\text { [glucose] }} \mathrm{dt} \text { (maternal plasma) }}
$$

where [2DG6P] is the fetal tissue activity of $\left[{ }^{3} \mathrm{H}\right] 2 \mathrm{DG} 6 \mathrm{P}$ at 45 min, [2DG]/[glucose] is the maternal plasma sp act of $\left[{ }^{3} \mathrm{H}\right] 2 \mathrm{DG}$, and $P_{k}$ is the ratio between fetal and maternal plasma sp act of $\left[{ }^{3} \mathrm{H}\right] 2 \mathrm{DG}$. Fetal tissue $\left[{ }^{3} \mathrm{H}\right] 2 \mathrm{DG} 6 \mathrm{P}$ activity and maternal plasma $\left[{ }^{3} \mathrm{H}\right] 2 \mathrm{DG}$ sp act were determined as previously described (3). The integral of the maternal $\left[{ }^{3} \mathrm{H}\right] 2 \mathrm{DG}$ sp act was obtained by establishing the best-fit curve using the double exponential equation: $y=A e^{B x}+C e^{D x}+E$, where $A, B, C, D$, and $E$ are constants chosen by a curve-fitting program (InPlot, Graph Pad, San Diego, CA). This equation provides a measure of relative glucose utilization, because differences may exist between 2DG and glucose with respect to cellular transport and phosphorylation.

$P_{k}$ values were determined separately in seven to nine litters for each of the four study groups. These values must be known because changes in maternal glucose metabolism or uterine blood flow may potentially alter tracer and glucose provision to the fetus. The maternal rat was anesthetized with $40 \mathrm{mg} / \mathrm{kg}$ i.v. pentobarbital, and an abdominal incision was made exposing the uterine horns. $\left[{ }^{3} \mathrm{H}\right] 2 \mathrm{DG}$ was injected into the maternal jugular catheter and maternal arterial blood was collected at the same time intervals as before. Immediately after obtaining each maternal sample, a small hysterotomy was made and a fetus was exposed, leaving the uteroplacental-fetal circulation intact. The fetal axillary artery was then severed and blood was collected approximately $1 \mathrm{~min}$ after the maternal sample. Fetal blood samples were generally obtained at 2, 4, 6, 11, 16, 21, 26, 31, 36, and $44 \mathrm{~min}$ after the 2DG injection by sequential sampling of multiple fetuses in each litter. The integrals of the fetal and maternal $\left[{ }^{3} \mathrm{H}\right] 2 \mathrm{DG}$ sp act were determined as previously described (3).

Tissue weight. In a separate study, minipumps were placed on d 15 or 18 of gestation. Hypoglycemic and control mothers were either delivered operatively on $\mathrm{d} 20$ or allowed to deliver at term. After decapitation, tissues were removed, blotted dry, frozen in liquid nitrogen, and weighed. The weight of the carcass (body after decapitation and removal of viscera) was used as a measure of total muscle mass. Hind limb muscles were analyzed for water, protein, and DNA content. Tissues were either dried at $40^{\circ} \mathrm{C}$ for $18 \mathrm{~h}$ to determine water content or homogenized in normal saline (Duall tissue grinder) for spectrophotometric analysis of protein $(10,11)$ and total DNA content $(12,13)$.

Statistical analysis. Fetal tissue rGU and $P_{k}$ values were analyzed with two-way analysis of variance using treatment and duration as main effects. All other group comparisons were made using one-way analysis of variance. Data obtained from multiple fetuses in a single litter were averaged. Each litter represented a single experiment. Data are presented as mean \pm SEM.

\section{RESULTS}

Plasma glucose and insulin concentrations. Insulin infusions resulted in elevated maternal plasma insulin concentrations on d 20 of gestation $(449.2 \pm 55.9$ versus $27.2 \pm 2.6 \mu \mathrm{U} / \mathrm{mL}, p<$ 0.001 ) and diminished glucose concentrations from $24 \mathrm{~h}$ after pump placement to d 20 (Fig. 1). Fetuses from hypoglycemic maternal rats had significantly lower plasma glucose and insulin concentrations on d 20 (Fig. 2). Fetal/maternal glucose ratios were similar between hypoglycemic and control rats $(0.70 \pm 0.02$ versus $0.69 \pm 0.01, p=0.74)$.

$P_{k}$. Figure 3 depicts a typical course of $\left[{ }^{3} \mathrm{H}\right] 2 \mathrm{DG}$ sp act in maternal and fetal plasma during a sample $P_{k}$ determination. $P_{k}$ values after $2 \mathrm{~d}$ of hypoglycemia ( $1.00 \pm 0.05$ versus $1.12 \pm 0.02$, $p<0.05)$ and $5 \mathrm{~d}$ of hypoglycemia $(0.97 \pm 0.05$ versus $1.12 \pm$ $0.02, p<0.05$ ) were less than their respective control values.

$r G U$. Both 2 and $5 \mathrm{~d}$ of hypoglycemia were associated with diminished rGU of fetal liver, lung, and muscle on d 20 (Fig. 4). Kidney also demonstrated lower rGU after 2 and $5 \mathrm{~d}$ of hypoglycemia, but to a lesser degree (Fig. 5). Fetal heart rGU was diminished after $2 \mathrm{~d}$ of hypoglycemia but was not affected by 5 $\mathrm{d}$ of hypoglycemia. There were no differences in placental rGU between hypoglycemic and control rats after either duration of hypoglycemia; however, the rGU of both $5 \mathrm{~d}$ hypoglycemia and $5 \mathrm{~d}$ control placentas were greater than their respective 2-d values. Of note, brain rGU was increased after 2 and $5 \mathrm{~d}$ of hypoglycemia (Fig. 5).

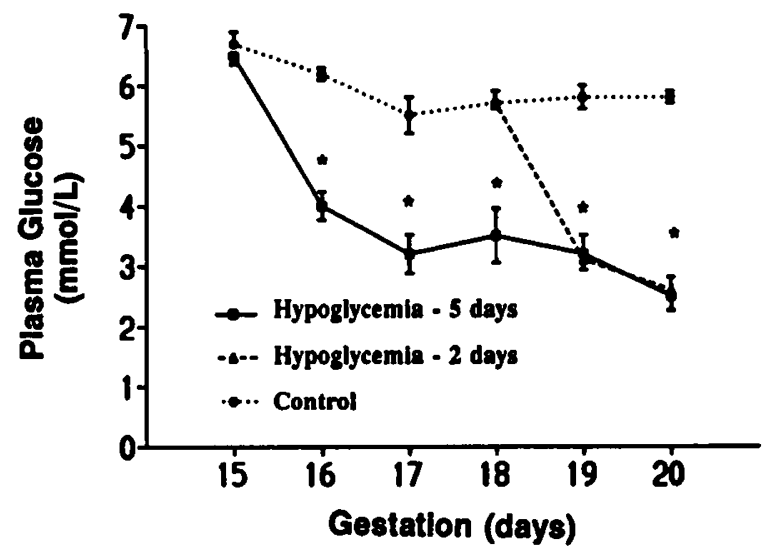

Fig. 1. Maternal plasma glucose concentrations before and after initiation of continuous insulin infusions on $\mathbf{d} 15$ of gestation (solid line) or on d 18 of gestation (dashed line) vs control (dotted line). ${ }^{*}, p<0.001$, hypoglycemia $v s$ control.

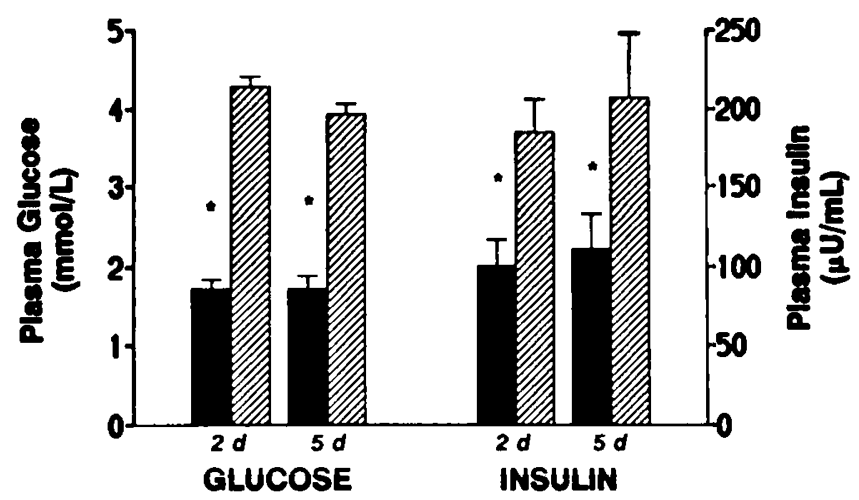

Fig. 2. Fetal plasma glucose and insulin concentrations on d 20 of gestation after 2 or $5 \mathrm{~d}$ of maternal insulin-induced hypoglycemia (solid bars) vs control (hatched bars). ${ }^{*}, p<0.05$, hypoglycemia vs control. 


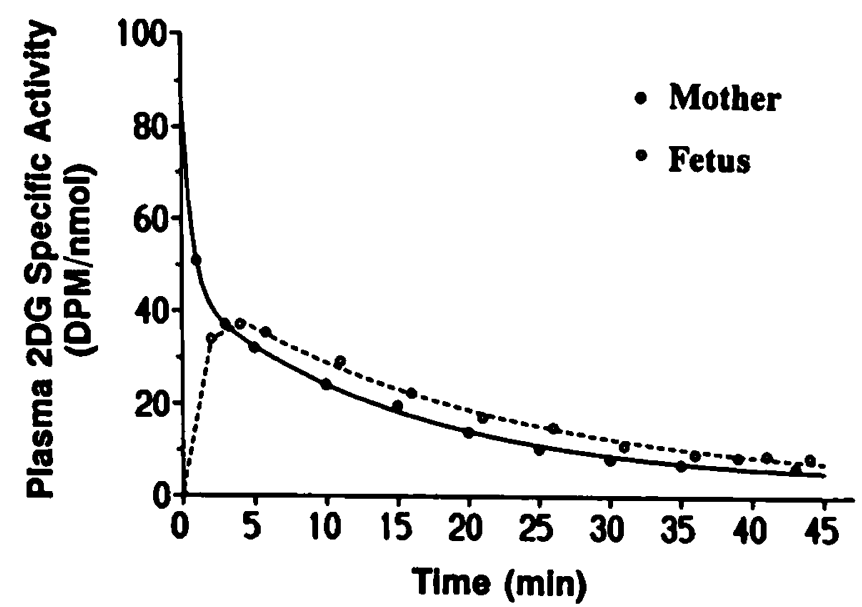

Fig. 3. 2DG sp act in maternal and fetal plasma after a maternal i.v. injection of $\left[{ }^{3} \mathrm{H}\right] 2 \mathrm{DG}$. The ratio of the areas under the fetal and maternal curves is equivalent to $P_{k}$.

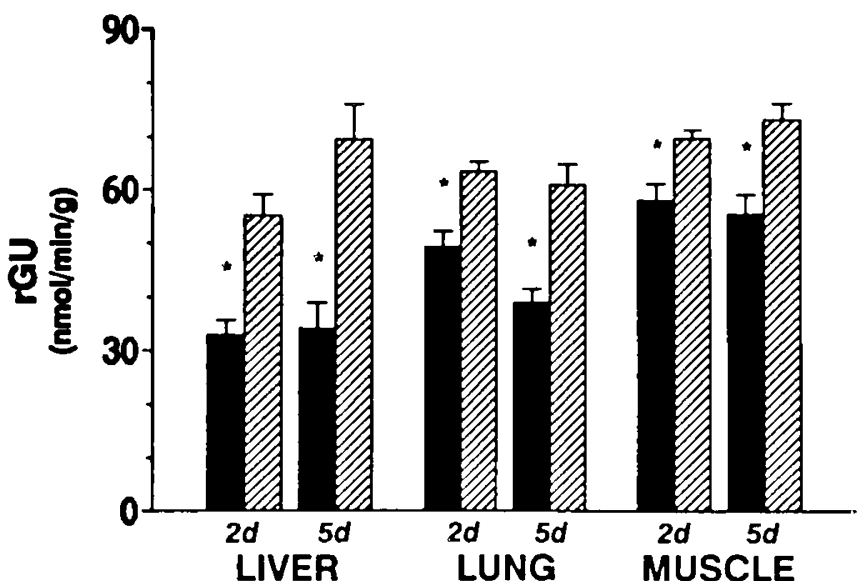

Fig. 4. reit of fital liver. lung. and muscke on d 20 of gestation after 2 or $5 \mathrm{~d}$ of maternal hypoglycemia ( weld har ) in control (hatched hars). *, $p<0.001$. hypoglycemial in control

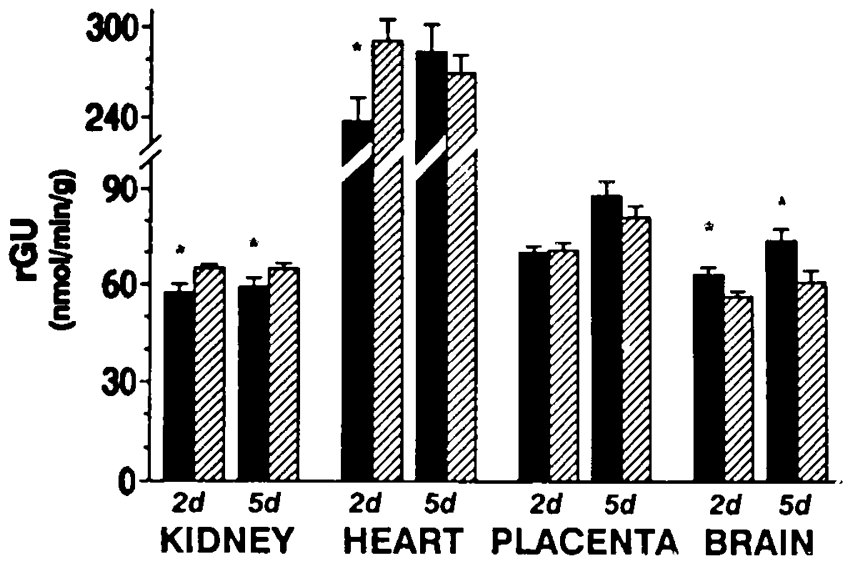

Fig. 5. rGU of fetal kidney, heart, placenta, and brain on d 20 of gestation after 2 or $5 \mathrm{~d}$ of maternal hypoglycemia (solid bars) vs control (hatched bars). ${ }^{*}, p<0.05$, hypoglycemia vs control.

Fetal and newborn weight. Five days, but not 2 d, of hypoglycemia produced mild fetal growth retardation by $\mathrm{d} 20$ of gestation (Table 1). Fetal liver weight was diminished after $5 \mathrm{~d}$ of hypoglycemia; otherwise no weight differences were observed between hypoglycemic fetal tissues and controls. At term, newborn offspring of hypoglycemic mothers were significantly lighter than controls after either duration of hypoglycemia (Table 1). Liver, lung, and carcass from these growth-retarded newborns weighed less than their respective control tissues, whereas kidney, heart, and brain weights were similar. Hypoglycemia of either duration did not affect water, protein, or total DNA content of fetal tissues on d 20 of gestation (Table 2).

\section{DISCUSSION}

This study demonstrates that limited glucose availability to the fetus affects organ rGU and growth in a tissue-specific manner. Furthermore, our data indicate an association between fetal tissue rGU and growth, inasmuch as fetal tissues that are undergrown in this model of IUGR (liver, lung, and muscle) have marked reductions in rGU after 2 and $5 \mathrm{~d}$ of limited glucose availability.

To limit fetal glucose availability, maternal rats were rendered hyperinsulinemic and consequently hypoglycemic. This procedure results in fetal hypoglycemia within $24 \mathrm{~h}$ of minipump placement and throughout the remainder of gestation (6). Fetal hypoinsulinemia also occurs because insulin does not appreciably cross the placenta. Maternal hyperinsulinemia was initiated on either d 15 or 18 of gestation and rGU was measured on d 20 to determine fetal tissue response to short and long durations of fetal hypoglycemia and hypoinsulinemia. This allowed us to compare rGU on the same day of gestation. Initiating hypoglycemia on different days also seemed logical because the conditions that cause IUGR may begin early or late in gestation. Regardless of the timing of minipump placement, similar degrees of maternal hypoglycemia and fetal hypoglycemia/hypoinsulinemia were observed on $\mathrm{d} 20$.

Glucose utilization is regulated by several different processes including tissue demand, glucose availability, and the activity, type, and quantity of glucose transporters and hexokinases. Glucose transport and phosphorylation, aside from being influenced by tissue glucose requirements and availability, are also regulated by insulin. Thus, the finding of diminished rGU of fetal liver, lung, muscle, and kidney after 2 and $5 \mathrm{~d}$ of hypoglycemia and of heart after $2 \mathrm{~d}$ of hypoglycemia may be the result of decreased glucose availability or reduced insulin secretion.

The restoration of fetal heart rGU to normal after $5 \mathrm{~d}$ of hypoglycemia cannot be explained by higher fetal glucose or insulin concentrations because these were similar between 2 and $5 \mathrm{~d}$ of hypoglycemia. The improved rGU might have resulted from either increased myocardial blood flow, which would improve glucose supply, or more intrinsic adaptations involving increased glucose transport. Although the duration of hypoglycemia appears to be important for the restoration of fetal heart rGU, the stage of gestation at which maternal insulin infusions were initiated might also be contributory. The ability of the fetal heart to normalize rGU after $5 \mathrm{~d}$ of hypoglycemia may be the result of initiating hypoglycemia at an earlier gestational age.

The ability of fetal brain to increase rGU after 2 and $5 \mathrm{~d}$ of hypoglycemia may be related to a number of factors including a compensatory increase in cerebral blood flow, an increase in glucose transport, and its independence from insulin-mediated glucose transport. Increased cerebral blood flow has been demonstrated in IUGR human fetuses $(14,15)$ and hypoglycemic preterm neonates (16). The finding of preserved glucose transporter mRNA and protein levels in fetal brain and diminished levels in lung and muscle after uterine artery ligation (17) supports the possibility that fetal brain may up-regulate glucose transport during IUGR. Others have found a similar increase of brain glucose transport in chronically hyperinsulinemic, hypoglycemic adult rats (18). This apparent "overcompensation" could be due to reduced availability of other metabolic fuels. Our laboratory has shown diminished total amino acid plasma concentrations in pregnant rats and their fetuses after prolonged maternal insulin infusions (6), and others have found lower alanine concentrations (5). The reduction of these and other fuels may have increased the glucose demand by fetal brain. 
Table 1. Fetal and newborn body and tissue weight

\begin{tabular}{|c|c|c|c|c|c|c|c|c|}
\hline & Body (g) & $\begin{array}{l}\text { Liver } \\
(\mathrm{mg})\end{array}$ & $\begin{array}{l}\text { Lung } \\
\text { (mg) }\end{array}$ & Carcass (g) & $\begin{array}{c}\text { Kidney } \\
\text { (mg) }\end{array}$ & $\begin{array}{c}\text { Heart } \\
(\mathrm{mg})\end{array}$ & $\begin{array}{c}\text { Placenta } \\
(\mathrm{mg})\end{array}$ & $\begin{array}{l}\text { Brain } \\
(\mathrm{mg})\end{array}$ \\
\hline \multicolumn{9}{|l|}{ D 20 fetus } \\
\hline \multicolumn{9}{|l|}{ D 15 surgery } \\
\hline Hypoglycemia & $3.56 \pm 0.07^{*}$ & $217 \pm 11^{*}$ & $117 \pm 7$ & $1.83 \pm 0.08$ & $25.8 \pm 2.2$ & $15.5 \pm 0.9$ & $449 \pm 15$ & $162 \pm 6$ \\
\hline Control & $3.83 \pm 0.06$ & $253 \pm 03$ & $124 \pm 2$ & $2.01 \pm 0.02$ & $27.5 \pm 0.6$ & $17.9 \pm 1.1$ & $517 \pm 26$ & $162 \pm 2$ \\
\hline \multicolumn{9}{|l|}{ D 18 surgery } \\
\hline Hypoglycemia & $3.61 \pm 0.05$ & $215 \pm 09$ & $121 \pm 3$ & $1.86 \pm 0.05$ & $28.4 \pm 2.4$ & $17.0 \pm 0.9$ & $487 \pm 20$ & $164 \pm 5$ \\
\hline Control & $3.77 \pm 0.07$ & $240 \pm 07$ & $124 \pm 5$ & $1.93 \pm 0.06$ & $27.1 \pm 0.7$ & $16.7 \pm 0.2$ & $474 \pm 10$ & $161 \pm 6$ \\
\hline \multicolumn{9}{|l|}{ Newborn } \\
\hline \multicolumn{9}{|l|}{ D 15 surgery } \\
\hline Hypoglycemia & $5.53 \pm 0.13^{*}$ & $200 \pm 10^{*}$ & $93 \pm 3^{*}$ & $2.94 \pm 0.10^{*}$ & $53.1 \pm 1.6$ & $27.5 \pm 1.6$ & $\mathrm{~N} / \mathrm{A} \dagger$ & $255 \pm 9$ \\
\hline Control & $6.51 \pm 0.10$ & $245 \pm 07$ & $119 \pm 3$ & $3.43 \pm 0.06$ & $54.7 \pm 2.4$ & $31.2 \pm 1.1$ & N/A & $261 \pm 6$ \\
\hline \multicolumn{9}{|l|}{ D 18 surgery } \\
\hline Hypoglycemia & $5.36 \pm 0.06^{*}$ & $192 \pm 09^{*}$ & $93 \pm 3^{*}$ & $2.84 \pm 0.06^{*}$ & $48.2 \pm 1.9$ & $26.4 \pm 0.3$ & N/A & $240 \pm 7$ \\
\hline Control & $6.18 \pm 0.19$ & $236 \pm 10$ & $112 \pm 4$ & $3.28 \pm 0.10$ & $49.4 \pm 1.7$ & $30.1 \pm 0.9$ & $\mathbf{N} / \mathbf{A}$ & $248 \pm 6$ \\
\hline
\end{tabular}

$* p<0.05$, hypoglycemia vs control.

$+\mathrm{N} / \mathrm{A}$, measurements not available.

Table 2. Water, protein, and DNA content of fetal tissue on d 20 of gestation

\begin{tabular}{|c|c|c|c|c|c|c|c|}
\hline & Liver & Lung & Muscle & Kidney & Heart & Placenta & Brain \\
\hline \multicolumn{8}{|l|}{ Water (\%) } \\
\hline Hypoglycemia & $75.5 \pm 0.3$ & $87.5 \pm 0.3$ & $87.3 \pm 0.1$ & $87.2 \pm 0.2$ & $83.1 \pm 0.5$ & $84.6 \pm 0.2$ & $87.8 \pm 0.4$ \\
\hline Control & $74.9 \pm 0.3$ & $87.4 \pm 0.2$ & $86.8 \pm 0.1$ & $87.3 \pm 0.3$ & $83.0 \pm 0.6$ & $84.7 \pm 0.2$ & $88.3 \pm 0.2$ \\
\hline \multicolumn{8}{|c|}{ Protein ( $\mu \mathrm{g} / \mathrm{mg}$ dry tissue) } \\
\hline Hypoglycemia & $440 \pm 11$ & $505 \pm 17$ & $453 \pm 10$ & $545 \pm 11$ & $542 \pm 13$ & $670 \pm 28$ & $509 \pm 15$ \\
\hline Control & $411 \pm 09$ & $498 \pm 12$ & $451 \pm 11$ & $549 \pm 11$ & $531 \pm 15$ & $629 \pm 28$ & $541 \pm 14$ \\
\hline \multicolumn{8}{|c|}{ DNA ( $\mu \mathrm{g} / \mathrm{mg}$ dry tissue) } \\
\hline Hypoglycemia & $21.8 \pm 0.8$ & $42.5 \pm 1.3$ & $21.7 \pm 0.6$ & $45.1 \pm 1.1$ & $20.9 \pm 0.6$ & $11.2 \pm 0.6$ & $31.2 \pm 0.8$ \\
\hline Control & $22.6 \pm 1.2$ & $42.5 \pm 1.1$ & $20.8 \pm 0.4$ & $45.5 \pm 1.7$ & $19.8 \pm 0.4$ & $10.3 \pm 0.4$ & $33.9 \pm 0.8$ \\
\hline
\end{tabular}

Placental rGU (hypoglycemic and control) was significantly greater when surgery was performed on d 15 compared to $d 18$. This effect is likely due to the timing of anesthesia and did not otherwise produce significant differences between $2-$ and 5-d control tissues.

We previously demonstrated increased rGU of fetal liver, muscle, kidney, and heart and normal rGU of fetal brain $2 \mathrm{~d}$ after maternal uterine artery ligation. Uterine artery ligation, like maternal hyperinsulinemia, is associated with fetal hypoglycemia. It also alters placental gaseous exchange, resulting in fetal hypoxia, hypercapnia, and acidosis (4). These variables are normal during maternal hyperinsulinemia (6). The differences in rGU between the two models of IUGR might be attributed to altered gaseous exchange resulting from uterine artery ligation. Fetal hypoxia may increase anaerobic metabolism and, consequently, glycolysis.

We used a modification of Sokoloff's 2DG method to measure fetal tissue rGU. An important limitation of this methodology is that only relative glucose utilization rates can be determined. Measurements of actual glucose utilization must take into account differences in transport and phosphorylation rates that exist between 2DG and glucose. These differences, which are represented by the "lumped constant" in Sokoloff's original description, cannot be determined in fetal tissue.

The original 2DG methodology has been validated for brain and has been used in several other tissues. However, measurements of glucose utilization in tissues capable of glucogenesis, e.g. liver, should be interpreted with caution. Glucose-6-phosphatase is capable of converting 2DG6P back to 2DG. Although glucose-6-phosphatase is present in rat liver and kidney, its activity is very low in fetal life $(19,20)$. However, fetal hypoglycemia, when produced by maternal insulin infusions, has been shown to increase fetal liver glucose-6-phosphatase activity (21). This increase may partially account for the lower rGU of hypoglycemic fetal liver.

The measurement of rGU in fetal tissues requires the deter- mination of $P_{k}$, which is the ratio of fetal to maternal 2DG sp act. The lower $P_{k}$ values of hypoglycemic rats may have resulted from the more rapid decline of plasma $\left[{ }^{3} \mathrm{H}\right] 2 \mathrm{DG}$ sp act in hyperinsulinemic compared to control maternal rats. At the time of its appearance in the fetal plasma, a greater portion of the tracer was already metabolized by the mother. Another possible explanation accounting for the lower $P_{k}$ of hypoglycemic rats is increased fetal gluconeogenesis. This would lower the fetal 2DG sp act and thus reduce $P_{k}$. The use of $P_{k}$ takes these differences into account and assures the validity of the methodology.

We were able to produce a mild degree of IUGR by d 20 of gestation after $5 \mathrm{~d}$ (but not $2 \mathrm{~d}$ ) of hypoglycemia. At term, significant reductions in the weight of newborns of hypoglycemic mothers were seen regardless of the duration of insulin infusion. This is not surprising because a large portion $(\sim 40 \%)$ of fetal growth occurs between $\mathrm{d} 20$ and term. At term, the weights of liver, lung, and carcass were reduced in both hypoglycemic groups, whereas the weights of kidney, heart, and brain were not significantly affected. Those fetal tissues exhibiting poor growth in this model of IUGR demonstrate analogous changes in rGU. We speculate that fetal tissue growth and glucose utilization are influenced by similar mechanisms and that glucose utilization may be an important determinant of fetal tissue growth. The differences between this model and that of uterine artery ligation with respect to fetal tissue glucose utilization underscore the importance of the effects of hypoxia and acidosis upon fetal glucose metabolism.

\section{REFERENCES}

1. Economides DL, Proudler A, Nicolaides KH 1989 Plasma insulin in appropriate- and small-for-gestational-age fetuses. Am J Obstet Gynecol 160:10011094

2. Economides DL, Nicolaides KH 1989 Blood glucose and oxygen tension levels in small-for-gestational-age fetuses. Am J Obstet Gynecol 160:385-389

3. Lueder FL, Ogata ES 1990 Uterine artery ligation in the maternal rat alters fetal tissue glucose utilization. Pediatr Res 28:464-468

4. Ogata ES, Bussey M, Finley S 1986 Altered gas exchange, limited glucose and 
branched chain amino acids, and hypoinsulinemia retard fetal growth in the rat. Metabolism 35:970-977

5. Gruppuso PA, Migliori A, Susa JB. Schwartz R 1981 Chronic maternal hyperinsulinemia and hypoglycemia. Biol Neonate 40:113-120

6. Ogata ES, Paul RI, Finley SL 1987 Limited maternal fuel availability due to hyperinsulinemia retards fetal growth and development in the rat. Pediatr Res 22:432-437

7. Sokoloff L, Reivich M. Kennedy C, Des Rosiers MH, Patlak CS, Pettigrew KD, Sakurada O, Shinohara M 1977 The $\left[{ }^{14} \mathrm{C}\right]$ deoxyglucose method for the KD, Sakurada O, Shinohara Marement of local cerebral glucose utilization: theory, procedure, and normal values in the conscious and anesthetized albino rat. J Neurochem 28:897-916

8. Leturque A, Hauguel S, Kande J, Girard J 1987 Glucose utilization by the placenta of anesthetized rats: effect of insulin. glucose, and ketone bodies. Pediatr Res 22:483-487

9. Leturque A, Revelli JP, Hauguel S, Kande J, Girard J 1987 Hyperglycemia and hyperinsulinemia increase glucose utilization in fetal rat tissues. Am J Physiol 253:E616-E620

10. Lowry OH, Rosebrough NJ, Farr AL, Randall RJ 195! Protein measurement with the Folin phenol reagent. J Biol Chem 193:265-275

11. Ohnishi ST. Barr JK 1978 A simplified method of quantitating protein using the biuret and phenol reagents. Anal Biochem 86:193-200

12. Burton $\mathrm{K} 1956 \mathrm{~A}$ study of the conditions and mechanism of the diphenylamine reaction for the colorimetric estimation of deoxyribonucleic acid. Biochem J 62:315-323

13. Gendimenico GJ, Bouquin PL, Tramposch KM 1988 Diphenylamine-colori- metric method for DNA assay: a shortened procedure by incubating samples at $50^{\circ} \mathrm{C}$. Anal Biochem 173:45-48

14. Arduini D, Rizzo G, Romanini C, Mancuso S 1987 Fetal blood flow velocity waveforms as predictors of growth retardation. Obstet Gynecol 70:7-10

15. Wladimiroff JW, Van Den Wijngaard JAGW, Degani S, Noordam MJ, Van Eyck J. Tonge HM 1987 Cerebral and umbilical arterial blood flow velocity waveforms in normal and growth-retarded pregnancies. Obstet Gynecol 69:705-709

16. Pryds O. Christensen NJ, Friis-Hansen B 1990 Increased cerebral blood flow and plasma epinephrine in hypoglycemic, preterm neonates. Pediatrics 85:172-176

17. Simmons RA, Gounis AS, Bangalore SA, Ogata ES 1991 Intrauterine growth retardation: fetal glucose transport is diminished in lung but spared in brain. Pediatr Res 1:59-60

18. McCall AL, Fixman LB, Fleming N, Tornheim K, Chick W, Ruderman NB 1986 Chronic hypoglycemia increases brain glucose transport. Am J Physiol 251:E442-E447

19. Burchell A, Leakey JEA 1988 Development of the rat hepatic microsomal glucose-6-phosphatase system and its glucocorticoid inducibility. Biol Neonate 54:107-115

20. Burch HB, Kuhlman AM, Skerjance J, Lowry OH 1971 Changes in patterns of enzymes of carbohydrate metabolism in the developing rat kidney. Pediatrics 47:199-206

21. Domenech D, Gruppuso PA. Susa JB, Schwartz R 1985 Induction in utero of hepatic glucose-6-phosphatase by fetal hypoinsulinemia. Biol Neonate 47:92-98 